\title{
A SOCIEDADE: TENDÊNCIAS DE CONSUMO E A ÉTICA EMPRESARIAL
}

Adriano Fábio Cordeiro da Silva

Doutorando do Programa de Pós-graduação em Direito da Pontifícia Universidade Católica do Paraná (PUCPR), Área de concentração: Direito Econômico e Socioambiental.E-mail: adrianofabio@hotmail.com

AntônIo Carlos Efing

Professor titular da Pontifícia Universidade Católica do Paraná (PUCPR). Professor Permanente dos Programas de Pós-Graduação em Direito (PPGD). Doutor em Direito das Relações Sociais - PUC/SP. E-mail: ace@eradv.com.br

\section{Resumo}

O presente trabalho analisa a sociedade, as tendências de mercado e a ética empresarial aplicada ao consumo. A metodologia utilizada é a pesquisa bibliográfica, abrange os diversos meios de informação, priorizando-se a doutrina inerente aos temas tratados, os sites da internet, as revistas especializadas e outras fontes que como subsídio para o embasamento teórico. Discute a diferença entre consumo, consumismo e hiperconsumismo. Conceitua os modismos, as tendências e megatendências do mercado e faz consideraçôes sobre o perfil do consumidor do futuro. Verifica que o crédito facilita o fenômeno do hiperconsumo e do superendividamento. Trabalha a relação do marketing, enquanto agente promotor das marcas, propagandas e publicidade. Aborda a Ética aplicada ao consumo enquanto ciência que se relaciona com a Economia e com o mercado consumidor.

\section{Palavras-chave}

Sociedades; Tendências; Ética; Consumo; Economia.

\section{Abstract}

This paper analyzes the society, the market trends, and the business ethics applied to consumption. The methodology used in this study is the literature search, covering the different media, giving priority to the doctrine inherent in the concerned themes, the websites, the specialized magazines, and other sources for theoretical basis. This study discusses the difference among consumption, consumerism, and hyperconsumerism; 
conceptualizes the fads, trends, and megatrends in the market and raises questions about the future consumer profile; verifies that credit facilitates the phenomenon of hyper-consumption and over-indebtedness. It works the relation of marketing as propellant brands, advertisements, and advertising; addresses the Ethics applied to consumption as a science that relates to the economy and the consumer market.

\section{Key words}

Companies; Trends; Ethics; Consumption; Economy.

\section{Introdução}

Os comportamentos e expectativas dos seres humanos, especialmente aqueles vivenciados pelo ato de consumir, podem gerar diversas formas de consumo, cujo estudo constitui um dos objetivos desta pesquisa que, também tem por finalidade analisar a importância da ética empresarial aplicada ao consumo e associada à economia. O dinamismo competitivo do mercado favorece o surgimento das tendências que orientam os comportamentos e estratégias empresariais que buscam satisfazer e fidelizar os consumidores.

Estamos numa sociedade caracterizada por qual tipologia de consumo? Qual a diferença entre consumo, consumismo e hiperconsumo? Quais as principais tendências do mercado? Qual o perfil do consumidor no futuro? Qual a importância da ética empresarial aplicada ao consumo?

A metodologia utilizada foi a pesquisa bibliográfica, abrangendo os diversos meios de informação, priorizando-se a doutrina inerente aos temas tratados, os sites da internet, as revistas especializadas e outras fontes que serviram como subsídio para o embasamento teórico, especialmente, enriquecida com alguns pronunciamentos em entrevistas publicadas e concedidas por renomados autores, almejando uma análise crítica quanto ao futuro da sociedade sobre os temas aqui tratados.

\section{A Sociedade Atual e a Cultura do Consumo}

Com as atuais sociedades caracterizadas pelo modo de produção em massa ${ }^{1}$, pela abundância, pela hiperprodução ${ }^{2}$ de produtos e serviços surge também o fenômeno do

1 É uma forma de fabricar produtos que tira o poder de escolha do consumidor e o coloca nas mãos dos fabricantes, que produzem sem saber se haverá compradores. Segundo Adam Smith (1776) A produção em massa foi utilizada pela primeira vez nos Estados Unidos nas fábricas de armas no fim do século XVIII. A mão de obra especializada é utilizada na criação e na organização do sistema de produção e a não especializada é colocada na linha de montagem.

2 Excesso de produção ou produtividade excessiva. 
hiperconsumismo. Este fenômeno provoca uma série mudanças comportamentais nos integrantes do mercado de consumo ${ }^{3}$.

No que tange aos consumidores, percebe-se que eles se encontram pautados pela busca imediata do prazer de consumir, pela satisfação urgente dos desejos e pelo crescente individualismo. É a apologia da satisfação imediata e a qualquer preço, em que a limitação do recurso financeiro próprio foi substituída pela indústria e serventia do crédito, que, além de antecipar desejos, também massifica a dependência dos consumidores face aos serviços creditícios promovidos pelas instituiçóes financeiras.

Neste sentido, Mário Ernesto René Schweriner ${ }^{4}$, (2006, p. 138), ao tratar sobre a história da atual sociedade e cultura do consumo, observa que:

Um contraponto interessante pode ser estabelecido no século XIX, época em que o incentivo às massas era no sentido da economia, da poupança. Era inconcebível que as pessoas incorressem em gastos que não pudessem ser pagos imediatamente, isto é, que comprassem sem que tivessem à mão ou no banco o dinheiro correspondente. Há diferença para os tempos atuais, em que o consumidor é incitado a comprar continuamente, mesmo sem dinheiro para isso, valendo-se da instituição do crédito para viabilizar o moto contínuo do consumo. Além disso, subjacente a esse giro permanente, reside o incentivo ao descartável, quer dizer, a se desfazer das mercadorias rapidamente. $\mathrm{O}$ contato do possuidor com o bem é fugaz, ao contrário dos séculos precedentes, quando a posse era valorizada. O caráter social do século XIX pode ser definido como tendo por principal objetivo a posse, enquanto o caráter social do século XX tem por objetivo o uso. Não queremos dizer que essa alteração de foco, da posse para o uso, seja necessariamente negativa. O lado destrutivo repousa no fato de se desfazer de bens que mal foram usados, pois o consumidor é estimulado, ou melhor, condicionado a trocá-los por novos produtos.

Sendo assim foi, precisamente no século XX e início do século XXI, que surgiu e se estimulou um novo perfil de comportamento do consumidor frente às facilidades do crédito, impulsionado e ofertado pelos bancos e instituiçóes financeiras, inclusive, em alguns momentos, de forma predatória, facilitando-se o aparecimento do fenômeno social nocivo a que chamamos hiperconsumismo e o fenômeno jurídico do superendividamento. Nesse sentido, o professor Antônio Carlos Efing (2012, p. 674) afirma que o "superendividamento dos consumidores apresenta-se como desafio ao desenvolvimento sustentável da economia”.

3 O consumidor, o fornecedor, os produtos e os serviços.

4 Formado em Administração de Empresas pela Fundação Getúlio Vargas - FGV, psicólogo e mestre em Psicologia pela Universidade de São Paulo - USP e doutor em Teologia Prática (Ciências da Religião) pela Universidade Metodista. 
Entre os diversos autores que também analisam o crédito e a sociedade de consumo contemporânea, cumpre citar o conceituado sociólogo polonês Zygmunt Bauman, autor de uma produção intelectual prodigiosa e reconhecido como o pensador dos tempos líqui$\operatorname{dos}^{5}$, que amplifica os problemas gerados pelo excesso de crédito na sociedade moderna.

Em entrevista concedida ao jornalista Silio Boccanera, em 27 de janeiro de 2012, no programa Milênio da Globo News, Zygmunt Bauman assim se posicionou:

O crescimento econômico dos últimos 20, 30 anos, deveu-se inteiramente ao uso de dinheiro que não estava em nossas mãos. "Aproveite agora e pague depois." A filosofia era essa. Há 30 anos, trocamos o cartel das cadernetas de poupança pelo dos cartôes de crédito, que é exatamente o oposto. E chegou a hora de encarar as consequências disso. Os imensos valores pagos aos bancos para se recapitalizarem, pelos governos, terão que ser pago por nossos filhos e netos. Nós hipotecamos o futuro. Não para nossa geração, mas para as geraçóes futuras.

Assim Bauman aceita que as sociedades atuais podem ser definidas como sociedade lastreadas no crédito e no consumo.

Outro autor que aborda os aspectos inerentes a sociedade de consumo e ao consumismo é Colin Campbell, considerando sua defesa de que o consumismo contribui, positivamente, para a construção da identidade do sujeito. Para Campbell, os sentimentos do hedonismo e de daydream estão no âmago da sociedade de consumo. Por Hedonismo entende-se as açóes e vivências comportamentais que buscam, em primazia desenfreada, a satisfação pelo prazer e por daydream ${ }^{6}$, advindo das sensaçóes geradoras por prazeres imaginativos provenientes das aquisiçôes, do consumo e das compras.

Ainda segundo Márcio Ernesto René Schweriner (2006, p. 141)

Ancorado no hedonismo e no daydream, Campbell é ousado: para ele a sociedade de consumo é tudo, menos materialista. Claro, pois ao contrário do acúmulo de bens, em que posse e uso perduraria por longo tempo, presenciamos o descarte contínuo das mercadorias, substituídas por novidades que ao menos prometem novas emoções e daydreams. Todavia, como os desejos, as emoçóes e os daydreams de longe suplantam o que a realidade tem a oferecer, na forma de mercadorias, tais bens avidamente adquiridos jamais satisfazem o consumidor, que assim é permanentemente seduzido pela oferta de mais novidades envoltas em promessas de

5 Segundo Zygmunt Bauman, tempos líquidos é um fenômeno que caracteriza a vida nas grandes metrópoles globalizadas. Neste sentido, as cidades são hoje verdadeiros campos de batalha, onde poderes globais se chocam com identidades locais. O resultado desta equação é a eclosão nímia da violência e da insegurança.

6 Em tradução livre, devaneio, sonho acordado. 
emoções e daydreams, atrás das quais lá vai ele, quase que numa espiral infinita.

Diante das afirmaçóes de diversos autores, interessa analisar o posicionamento do filósofo francês Gilles Lipovetsky ${ }^{7}$ (2007):

O homem contemporâneo viveria em um estado de desamparo, tornando-se o único responsável por atingir seu êxito. Estaria suscetível a medos, frustraçóes, ansiedades e à produção de novas e efêmeras necessidades de consumo - consumo que perpassa as aquisiçóes materiais e chega ao domínio das subjetividades. De acordo com as reflexóes de Lipovetsky, a nova ordem cultural na contemporaneidade valoriza os laços emocionais e sentimentais, as trocas íntimas entre as pessoas e a proximidade comunicacional com o outro. $\mathrm{O}$ autor, discorrendo sobre a felicidade associada ao amor, afirma que em uma sociedade que não cessa de prestar culto ao ideal amoroso e na qual a verdadeira vida está associada ao que se saboreia a dois, a relação estável e exclusiva constitui ainda um fim ideal. Segundo esse filósofo, o valor reconhecido no amor e no sentimento, a busca de uma intimidade relacional, a necessidade de sentido intenso na vida e na relaçáo com o outro trabalham, fora de todo princípio moral, para privilegiar o laço estável. A família e as relaçóes afetivas não são valorizadas apenas porque as identificamos a uma vida rica em emoçóes e sentido, mas também porque nos permite realizar uma das aspiraçóes mais profundas dos seres: ser reconhecido como uma subjetividade insubstituível. ${ }^{8}$

Pode-se dizer que o mercado de consumo convive com práticas que estimulam, seduzem e influenciam os indivíduos a consumir cada vez mais. Entretanto, deve-se separar, distinguir o que é consumo, consumismo e hiperconsumo.

\subsection{Consumo, Consumismo e Hiperconsumo}

Pode-se atribuir ao verbo consumir o significado gastar ou corroer até a exaustão: devorar, destruir, extinguir, aniquilar, anular, enfraquecer, abater, desgostar, afligir, mortificar, fazer esquecer, apagar, esgotar. Ao analisar essas definiçóes, percebe-se que em todas elas se consubstancia uma simbólica ação de destruir, corroer e modificar a essência do que é ou pode ser consumido. Há, nesta observação, algo de semelhante ao que ocorre

7 Professor de filosofia na Universidade de Grenoble, autor de diversificadas obras sobre as sociedades contemporâneas, a exemplo dos livros, A Era do Vazio - O Luxo Eterno - O Crepúsculo do Dever e "A era do hiperconsumo e a felicidade paradoxal" que em seu conjunto, refletem a preocupaçáo do autor com o que designa ser a paradoxal perspectiva de felicidade atrelada aos modos de consumo nas práticas sociais e culturais no mundo contemporâneo.

8 COMIN, Fabio Scorsolini. Resenha: A felicidade paradoxal: ensaios sobre a sociedade de hiperconsumo de Gilles Lipovetsky. 
com todos os envolvidos nos processos produtivos e de comercialização inerentes à sociedade de consumo, nos quais o destruir, o construir, o fazer, o refazer, o disponibilizar, o ofertar e o comprar são etapas de um complexo processo de mercantilização e consumo característicos de uma sociedade, contraditoriamente, chamada de hipermoderna.

Longe da visão do consumo como algo pernicioso, como será adiante exposto no fenômeno do hiperconsumismo, o antropólogo Daniel Miller evidencia, em sua obra "Teoria das Compras", a representação do ato de comprar como uma expressão de amor, no sentido de fortalecimento dos laços de parentesco, analisando as compras como um rito devocional. $\mathrm{O}$ autor se contrapóe, portanto a teorias do consumo que entendem o comprar como um ato centrado no materialismo e no hedonismo.

Ana Beatriz Barbosa Silva (2014), autora do livro "Mentes Consumista", do consumo a compulsão por compras, destaca que:

Consumir é preciso e deve ser uma atividade salutar como tantas outras que fazem parte do cotidiano humano. A questão é se estamos preparados para ser bons consumidores. O bom consumidor satisfaz suas necessidades essenciais, permite-se a prazeres eventuais e, com o mínimo de planejamento, ainda consegue, dentre de suas possibilidades, fazem algum nível de poupança para os tempos mais difíceis. Estes sempre virão: todos estamos sujeitos às mares da vida: não existe ser humano que só tenham dias bons e vitórias intermináveis. Por isso, preparar-se para os dias que o mar não está para peixe, faz parte da sabedoria do bom viver. (p. 44)

Por certo, o consumo e o ato de consumir são inescapáveis à condição da existência e à necessidade de se perpetuar enquanto ser vivente. Discute-se, entretanto, a quantidade, a significação e a tipologia das diversas formas de consumo assumidas nas sociedades atuais, tendo-se como premissa que as matérias-primas são esgotáveis e que a finitude destes recursos é condição limitante deste modo de produção e de consumo em massa. Ruscheinsky (2012, p. 271) afirma que "O consumo é indispensável e cumpre diversas funçôes sociais, mas, nos níveis e padrões atuais, e em expansão, precisa ser modificado em direção a formas mais sustentáveis, tanto do ponto de vista social quanto ambiental".

Analisando-se a palavra "consumismo", verifica-se que o sufixo ismo remete ao exagero, acompanhado ou não de dependência. De certo, o consumismo afronta os limites impostos pela natureza e é tema de muitas discussóes. No âmago da discussão sobre consumismo, habita o conceito superlativo e exagerado do estado ou necessidade de consumo. Mesmo porque, o consumo satisfaz às necessidades, singulariza-se pelo que é essencial, enquanto que o consumismo está plasmado nos desejos que facilmente resvalam na direção do que é supérfluo, remetendo-se ao que é desnecessário.

Zygmunt Bauman (2008 apud DIEHL, 2014, p. 21), um dos sociólogos mais respeitados da atualidade, afirma que a economia consumista baseia-se no excesso e no 
desperdício para atender a todas as novas necessidades e impulsos, assim como oferecer novos mecanismos de motivação e orientaçáo da conduta humana. Bauman ainda assegura que o consumismo é também a "economia do engano", pois se apoia na irracionalidade e na emoção dos consumidores, ou seja, a sociedade de consumidores promove, encoraja ou reforça a escolha de um estilo de vida, rejeitando as opçóes culturais alternativas.

A hipérbole dos atos consumistas configura o quadro doentio do que se chama hiperconsumismo. Aqui se enquadram aqueles que Gilles Lypovesty classifica como integrantes da sociedade do hiperconsumo, o consumista turbinado:

O turboconsumidor individualista, flexível, hedonista, liberto das antigas culturas de classe está muito mais em busca de satisfaçóes emocionais imediatas que de demonstraçôes de condição social. O espírito de consumo infiltra-se nas relaçóes do consumidor com a família, com o trabalho, com a religião, com a política, com o lazer. Vivemos numa espécie de império do consumo em tempo integral, servido por um mercado diversifica do que, a uma só vez, satisfaze incentiva a ilimitada aspiração a novos prazeres. (2007, contracapa)

Ainda segundo Lypovesty, "na sociedade de hiperconsumo, as pessoas tendem a situar seus interesses e seus prazeres, em primeiro lugar, na vida familiar e sentimental, no repouso, nas férias e viagens, atividades de lazer e outras atividades associativas". (2007, p. 227)

No que tange aos fornecedores, primariamente, deve-se lembrar que os mesmos almejam amealhar lucros no mercado de consumo. Esta é uma de suas funções precípuas. Para a consecução desse objetivo, as instituiçóes empresariais se esmeram em antever e prover por meio dos seus produtos e serviços as necessidades e desejos dos consumidores, os quais podem ser inclusive estimulados por elas ao se utilizarem dos mecanismos múltiplos de propaganda ou de publicidade.

Afirma Gilcerlândia Pinheiro Almeida Nunes em sua resenha sobre o livro "A Felicidade paradoxal de Gilles Lipovetsky" publicada na Revista Inter-Legere no 05, que:

As transformaçôes dos indivíduos em relação à aquisição de bens, fez-se necessário um novo tipo de publicidade (com estratégias de segmentação ou melhor hipersegmentação) que estivesse realmente adequada para articular as marcas a uma ressignificação, ou seja, atualmente toda a construção do marketing não se liga mais à funcionalidade dos produtos, mas preocupam-se em criar uma alma, um "estilo de vida" associado àqueles nomes, muitas vezes falando de tudo menos do produto que está sendo vendido. Aliado a isso, uma nova abertura ou democratização do consumo através das massas. Não se ficam mais presos de um lado às necessidades, de outro, ao luxo, mas a todos é permitido voltar os olhos para o que é belo e de qualidade; fiam-se cada vez mais nas marcas graças ao processo 
de desregulamentação de classes. Os indivíduos parecem desnorteados sem as antigas amarras sociais e precisam assegurar-se em suas desorientaçôes que estão confiando em algo seguro, algo que possa amenizar suas ansiedades frente à desinstucionalização.

Os fornecedores compelidos pelas necessidades de implantar novas técnicas mercadológicas que cumpram o poder de atrair e fidelizar os consumidor, são desafiados a melhorar suas estratégias de marketing, para tanto, precisam antever e diferenciar o que são modismos, tendências e megatendências para a sociedade e o mercado de consumo atuais, tudo isto sem infringir e cometer aos princípios éticos empresariais que norteiam o ambiente concorrencial preconizado pela ordem econômica do mundo globalizado.

\subsection{Modismo, Tendências e Megatendência}

Sumariamente falando, entende-se por modismo os fenômenos de consumo imprevisíveis, temporalmente de curta duração e que se notabilizam por não apresentar grande significado social, econômico e político.

Entende-se, por tendência, acontecimentos que promovem direcionamentos no mercado de consumo e representam uma sequência considerável de eventos de oferta e de demanda, que tem força e durabilidade previsível. Revela como será tendenciosamente, o futuro do mercado, e oferece aos empresários, novas possibilidades de prever e antever os fluxos e atos consistentes de consumo.

A megatendência, por sua vez, é espécie de fenômeno de mercado, cuja singularidade é inerente as grandes mudanças sociais, econômicas, políticas e/ou tecnológicas. Formam-se e cristalizam-se lentamente no mercado de consumo, mas uma vez estabelecidas, influenciarão a ambiência mercadológica por longos períodos.

Analisando a obra de Kotler e Keller (2006), os mesmos confirmam que há uma distinção entre modismos, tendências e megatendências. Um modismo é imprevisível, de curta duração e não tem significado social, econômico e político. Já a tendência é mais previsível e duradoura que o modismo, oferece oportunidades e revela como será o futuro.

Como já previa a autora nova-iorquina Fairth Popcorn (1993), conhecida como a Nostradamus do marketing, uma tendência mercadológica pode se manter por muito tempo, em diferentes áreas de mercado e atividades, e pode ser confirmada por outros indicadores que surgem simultaneamente. Afinal, cada tendência é apenas parte do todo. Isso significa que as organizaçôes não devem caminhar exclusivamente na direção de uma única tendência, e sim entender como as tendências em sua totalidade definem o futuro. A autora afirma ainda que as tendências começam pequenas e depois ganham momentum. Se a organização puder estabelecer uma relação entre o aparecimento de uma 
tendência e seu impacto nos negócios, ela poderá ajustar seu produto à mesma, o que lhe dará uma vantagem competitiva sobre concorrência.

Para Philip Kotler (1998, p. 78), "tendência é uma direção ou sequência de eventos que ocorre em algum momento e promete durabilidade".

Já as megatendências, na opiniāo de Naisbitt e Aburdene (1990, p. 22) são

[...] grandes mudanças sociais, econômicas, políticas e tecnológicas que se formam lentamente e afetam as pessoas por um longo período de tempo, entre sete e dez anos ou até mais. Na visão dos autores, essas megatendências não aparecem e desaparecem de uma hora para outra.

Prospectar cenários de mercado de consumo passou a ser estratégico para os negócios das empresas, especialmente levando em consideração as megatendências que já vem sendo observadas na sociedade, na natureza e na economia. "Os processos de segmentação e estudo dos tipos de consumidores se revelam na integração da economia a sociedade para servir as necessidades humanas", segundo Peter Druckr (2002).

Segundo estudo da Fundação Dom Cabral, de autoria de Diogo Lacerda Santos e Hugo Ferreira Braga Tadeu (2014), são cinco as megatendências que influenciam as oportunidades de mercado de consumo:

Urbanizaçáo crescente: cidades de países em desenvolvimento vêm crescendo em grande escala. $\mathrm{O}$ deslocamento da populaçáo rural para os centros urbanos assume papel importante. Em países desenvolvidos, as cidades começam a se esgotar e ficar saturadas. Espera-se que a população urbana cresça $72 \%$ até 2050 (UN Department of Economic and Social Affairs, 2011 Revision), desse modo o investimento em desenvolvimento de infraestrutura torna-se fundamental para suprimir tais fatores.

Alteraçóes climáticas: a crescente demanda e a relativa escassez de recursos vêm ganhando importância nos debates atuais, principalmente por parte de ambientalistas devido às grandes alterações climáticas observadas. Merece destaque o provável aumento no preço de energia e commodities, fator crucial para o futuro panorama econômico mundial. Até 2030 , será necessário produzir $50 \%$ mais energia, e a população irá consumir $35 \%$ a mais de alimentos e $40 \%$ de água (National Intelligence Council, 2012). Percebe-se, portanto, a consequente necessidade de desenvolver novos tipos de energias alternativas não esgotáveis e tecnologias que otimizem a utilização de recursos naturais.

Mudanças no poder global: o elevado padrão de crescimento nos países em desenvolvimento, com destaque ao BRICS, chama atenção. Cada vez mais, as empresas desses países ganham importância no cenário econômico mundial, além disso, a elevada geração de capital, tecnologias e talentos também é bastante representativa. Entende-se que 
existe real potencial desses países assumirem papel de potências econômicas no médio/longo prazo, tornando-se líderes no cenário mundial. Em 2050, o PIB dos países considerados do E7 (China, Índia, Brasil, Turquia, México, Rússia e Indonésia) poderá chegar a US\$138,2 trilhōes, enquanto o PIB do G7 (Japão, EUA, Alemanha, Reino Unido, Itália e França) será o equivalente a US $\$ 69,3$ trilhóes no mesmo ano (PwC Analysis, 2009).

Mudanças demográficas: é possível identificar duas tendências relacionadas a esse aspecto: o crescimento elevado da populaçáo em países menos desenvolvidos e o gradual envelhecimento da população em países economicamente maduros. Em 2000, 10\% da população era idosa. Espera-se que esse número chegue a 21\% em 2050 (UN report World Population Ageing, 2001). A partir desse ponto, destacam-se dois fatores - a necessidade de investir e capacitar essa crescente população em países subdesenvolvidos, com o intuito de atender às demandas mundiais, suprindo também os espaços deixados por idosos que se tornaram improdutivos e, ainda, realizar mudanças institucionais que possibilitem governos e empresas bancarem gastos com a populaçáo idosa e aposentada.

Nova onda de inovaçóes: a geração de inovaçôes tecnológicas cresce em ritmo elevado nos últimos anos. Essas inovaçôes, além de alterar o paradigma da relação entre empresas e clientes, traz ganhos de produtividade e lucratividade para as empresas. O setor de telecomunicaçóes ganha destaque nesse aspecto, tendo em vista as grandes mudanças geradas na interaçáo entre pessoas na sociedade, de maneira rápida e inesperada. Espera-se que em 2020 existam 6,58 dispositivos por pessoa, conectados em algum tipo de rede. Esse número, em 2010, era de 1,84 aparelhos por pessoa (Cisco Internet Business Solutions Group, 2011).

Configura-se assim a importância com que as estratégias de marketing e seus estudos tem influenciado as decisóes corporativas com suas previsóes sobre os fluxos do consumo e dos consumidores.

\section{0 Consumidor do Futuro e as Tendências do Consumo no Brasil}

Segundo Takeshy Tachizawa", (2015, p. 5), "o consumidor do futuro, inclusive do Brasil, passará a privilegiar não apenas preço e qualidade dos produtos, mas principalmente o comportamento social e ambiental das empresas fabricantes destes produtos". Conforme afirmou Lívia Barbosa e Colin Campbell (2006, p. 8) "O consumo faz parte do dia a dia dos seres humanos" e "consumir é uma das mais básicas atividades do ser humano", para depois concluir a autora que "pode-se viver sem produzir, mas não sem consumir".

9 Doutor em Administração e Economia pela Fundação Getúlio Vargas - FGV. 
No que se refere as tendências de consumo no Brasil, apresentamos a seguir parte significativa de estudo que demonstram os comportamentos e tendências do consumidor brasileiro no futuro próximo, esta analise produzida pelo consultor da Macroplan ${ }^{10}$, Rodrigo Ventura (2010, p. 1), enumera nove tipos de tendências para os próximos 20 anos que impactarão decisivamente o perfil dos hábitos dos consumidores brasileiros.

1. Consumo exigente: maior exigência por produtos e serviços de qualidade, incluindo a valorização crescente da certificação e da rastreabilidade;

2. Consumo +60: aumento da demanda por produtos e serviços orientados ao consumidor com mais de 60 anos em virtude do envelhecimento populacional;

3. Consumo saudável: valorização da saúde nas decisôes de consumo e aumento da demanda por produtos e serviços orientados a uma vida saudável;

4. Consumo responsável: aumento da conscientização sócio-ambiental do consumidor e intensificação das exigências éticas e de eficiência no processo produtivo;

5. Consumo de baixa renda: ingresso de novos consumidores à economia de mercado e aumento da demanda por bens de consumo popular pelas classes de baixa renda (C, D e E);

6. Consumo precoce: aumento do poder de decisão de compra exercido pelas crianças e adolescentes sobre o consumo familiar;

7. Consumo online: aumento das transaçóes comerciais utilizando a Internet;

8. Consumo prático: aumento da demanda por produtos e serviços de elevada praticidade e que contribuam para a otimizaçáo do tempo;

9. Consumo em nichos: aumento da procura por serviços e produtos direcionados a mercados (públicos) específicos (portadores de necessidades especiais, GLS e afrodescendentes, entre outros).

Diante das tendências expostas e frente ao perfil de consumidor da sociedade contemporânea, deve-se analisar o impacto e a interligação destas tendências mercadológicas, especialmente quando confrontadas com o fenômeno do hiperconsumismo.

Se por um lado, temos uma sociedade mais abundante, especialmente no que tange a variedade de produtos e serviços expostos e disposto no mercado de consumo, o excesso

10 Empresa brasileira com mais de 20 anos de experiência em consultoria de cenários prospectivos, administração estratégica e gestão orientada para resultados. Com sedes no Rio de Janeiro, São Paulo e Brasília. 
de aquisiçóes e o acúmulo desnecessário de produtos e serviços pode promover aquilo que os autores chamam de consumismo, ou seja, o consumo desnecessário, especialmente quando observado face as aquisiçóes ditas supérfluas.

Hodiernamente, parece ser cada vez mais difícil, ante ao excesso da oferta e ao novo estilo de vida assumido pela hipermodernidade, decidir, racionalmente, o que é em si, e somente em si, consumo do que é indispensável e consumo do que é supérfluo.

Esta discussão entre o consumo indispensável e o supérfluo, é bastante antiga na sociedade, pois disso já nos alertava Max Weber (1864-1920) intelectual, jurista e economista alemão, considerado um dos fundadores da Sociologia, ao falar sobre o consumo dos supérfluos em seu livro A Ética Protestante e o Espírito do Capitalismo ${ }^{11}$ :

Este ascetismo secular protestante, agiu poderosamente contra o desfrute espontâneo das riquezas; restringiu o consumo, em espécie supérfluo. Por outro lado, teve o efeito psicológico de liberalização das inibiçôes da ética tradicional. Quebrou as amarras do impulso para a aquisição, não apenas legalizando-as, no sentido exposto, enfocando- o como desejado diretamente por Deus. A guerra contra as tentaçóes da carne, e da dependência das coisas materiais era, entre os puritanos, como disse expressamente o grande apologista do quakerismo Barklay, não uma guerra contra a aquisição racional, mas contra o uso irracional da riqueza.

Doutra feita, nos dias de hoje, é perceptível que se multiplicam os consumidores e indivíduos com práticas de consumo mais saudáveis e conscientes. Tratamos aqui de consumidores, cuja prática está preocupada com o futuro do planeta e com a escassez já sentida dos recursos naturais indispensáveis à sobrevivência da humanidade, especialmente das gerações futuras. Neste sentido, Antônio Carlos Efing (2011, p. 125) afirma que:

O conceito de desenvolvimento sustentável depende do conceito de consumo consciente. Este reflete a necessidade de os consumidores (de produtos e serviços) passarem a ser agentes de "controle crítico" do desenvolvimento sustentável, e isto só pode ser possível desapegando-se dos conceitos individualistas a respeito do que se consome, do que se utilizar, porque isto tem influência direta em todos os cidadãos e no próprio meio ambiente.

Entretanto, o hiperconsumo ainda será muito mais visível nos próximos anos, pois este movimento de conscientização pouco modificou o sistema capitalista de produção e venda de produtos e serviços.

11 Originalmente publicado no formato de dois extensos artigos em 1904-1905, a Ética Protestante e o Espírito do Capitalismo (em alemão Die protestantische Ethik und der 'Geist' des Kapitalismus) é uma obra produzida por Max Weber (1864-1920), considerado um dos fundadores do pensamento sociológico. 
Há de se descobrir formas da humanidade melhor distribuir seus avanços, riquezas, produtos e serviços de forma mais equânime, pois se de um lado temos o escracho moral do hiperconsumo, do outro temos a insensatez da miséria e da fome.

Neste contexto, a sociedade planetária parece tencionar as organizações a modificar e implantar condutas éticas mais responsáveis, especialmente porque, sendo elas as grandes ofertantes da abundância característica do mercado capitalista atual, onde tantas marcas, tantos concorrentes, tantas espécies e rotulagens de produtos e serviços, disputam avidamente pelos que podem consumir, a elas caberiam as primeiras modificaçóes comportamentais que, acompanhadas da responsabilização social, promovessem as mudanças que tornassem o acesso a estes produtos e serviços mais igualitários, mais respeitoso e menos indigno ao seres humanos consumidores.

Os governos também exigem das organizaçôes, especialmente das responsáveis pelos danos causados ao meio ambiente, mais responsabilidade na fabricaçáo de seus produtos e serviços, tendo esta responsabilidade socioambiental um importante papel na etapa de competição e, respectiva exposição da oferta no mercado de consumo.

\section{A Ética Empresarial Aplicada ao Consumo}

A ética aplicada ao contexto empresarial abrange a dinâmica comportamental interna e externa das mais diversas organizaçóes e empresas. Esta reflexão adentra ao entendimento das relações pertinentes as ciências da ética e da economia. A apresentação do livro sobre Ética e Economia do influente filósofo e economista indiano Amartya Sen (2006) expóe que:

A economia é parte de um todo. As questôes econômicas não são apenas questôes de praticidade e eficiência, mas também de moralidade e justiça. As questôes éticas não são apenas questôes de valor e intençôes generosas, mas também de lógica fria e exequibilidade. Se a economia desligada da ética é cega, a ética desligada da economia é vazia. O surpreendente não é que a teoria econômica e a reflexão ética voltem a caminhar juntas, mas que tenham permanecido divorciadas e incomunicáveis entre si por tanto tempo.

Tanto a Ética quanto a Economia, enquanto ciências, tem o mesmo objeto, estudam o homem, mas cada uma delas o analisa sob ângulos diferentes. A ética estuda as açóes do homem em relação à sua moralidade, isto é, julga se são boas ou más, diz respeito ao fim último do agir do homem, isto é, analisa se essas ações contribuem ou não para sua finalidade essencial. Já a economia estuda o homem e sua adaptação na sociedade, almejando a satisfação das suas necessidades por meios da escassez de recursos quantitativamente limitados. 
O economista Eduardo Giannetti ${ }^{12}$, em suas obras literárias assim questiona:

Qual a relação entre o ético e o útil? Que papel teriam virtudes como honestidade e confiabilidade no desempenho econômico de indivíduos, empresas e naçóes? Como definir e alcançar a justiça distributiva? O que fazer quando direitos individuais se chocam com o interesse público? Até que ponto valeria a pena sacrificar o nosso bem-estar em nome das geraçóes futuras? Qual o lugar do econômico na sociedade ideal?

Vê-se que relacionar a ética e a economia não é tarefa das mais fáceis, mas se sabe, que a ética não entra diretamente no mérito de como resolver o problema econômico, nem tem como função, apresentar soluçóes que são competência exclusiva das empresas e do governo, ou dos empresários ou economistas, porém, os economistas devem ter presente que o critério ético deve orientar o critério econômico, mas tudo isto perpassa pela urgência na promoção dos mecanismos públicos ou privados, que promovam, multipliquem e direcionem açóes educativas frente a problemática necessidade humana do consumo.

Para Ernesto Martins (2004, p. 27),

A educação para o consumo está apoiada em duas perspectivas: uma formação personalizada ou individualizada de conscientização ética, e uma formação social no âmbito de uma educação para a cidadania e tomada de consciência comunitária para a problemática do consumo e do ambiente. O objetivo final da educação para o consumo é que o sujeito seja autossuficiente e tenha domínio consciente do seu comportamento à volta das dependências negativas do consumo, além de ser capaz de agir comunitariamente, sendo solidário nas problemáticas consumistas.

Há muito tempo, mais precisamente em 1776, que Adam Smith ao publicar a obra a Riqueza das Naçóes, iluminou todo o mistério sobre o mercado produtivo com apenas um lampejo: "O consumo é o objetivo e o desígnio único de qualquer produção".

Nos dias atuais, os questionamentos se dão sobre os modelos produtivos e suas externalidades, sobre os conceitos de crescimento e desenvolvimento econômico, sobre a ética corporativa, a produção e o consumo conscientes, sobre a regulação estatal e as falhas de mercado.

Márcia Carla Ribeiro e Giovani Ribeiro Rodrigues Alves (2013, p. 152) afirmam que:

12 Economista brasileiro, formado na Faculdade de Economia, Administração e Contabilidade e em Ciências Sociais pela Faculdade de Filosofia, Letras e Ciências Humanas ambas da Universidade de São Paulo. É autor de diversos livros e artigos, tendo ganhado dois prêmios Jabuti: em 1994, com o livro Vícios privados, benefícios públicos? (Cia. das Letras, 1993) e, em 1995, com As partes \& o todo (Siciliano, 1995). Atualmente leciona no Insper. 
Mesmo que as empresas sejam os principais agentes econômicos e que o desenvolvimento das atividades empresariais pressuponha um ambiente de liberdade, não há como o Estado se omitir de interferir, seja para o aprimoramento das relaçóes econômicas, seja para minimizar efeitos negativos, seja para incorporar novas formas de organização.

Jean Tirole, economista francês, Prêmio Nobel de Economia 2014, faz contribuiçóes importantes, especialmente ao analisar o poder, a regulação e as falhas de mercado e diz que "é importante que o Estado regule certas atividades não para controla-las, mas para assegurar o bom funcionamento dos mercados e torna-los cada vez mais abertos e competitivos". Suas análises sobre empresas com poder de mercado resultaram em uma teoria unificada com uma forte influência sobre questóes políticas centrais: como o governo deveria lidar com fusóes e cartéis e como deveria regular os monopólios.

Justifica-se entáo o entendimento de que o ato de produzir e consumir, de forma semelhante as atividades humanas conscientes, são expressóes das liberdades e, por assim reconhecer, estão inseridos no âmbito da ética, refletem as escolhas e açóes dos indivíduos que têm de ser, portanto, explicita ou implicitamente justificados.

Uma ética do consumo é muito mais que uma reflexão sobre as condutas honestas ou desonestas num sistema de mercado, é muito mais que uma ética do consumidor, considerada uma subárea da ética do marketing. Trata de considerar um fenômeno, como o do consumo, que afeta todos os seres humanos, como um lugar privilegiado em que a economia se faz vida cotidiana e em que a vida cotidiana se economiza, com sua carga de motivaçôes, crenças, identidades, juízos e ideais morais. (GONÇALVES, 2013, 164)

Ana Beatriz Barbosa Silva (2014, p. 178)

A economia de mercado que alicerça nossos tempos nunca foi táo eficaz na produção de riquezas materiais. Hoje, no mundo inteiro, milhões de pessoas ascendem monetariamente e conquistam melhores padróes de vida; novos-ricos surgem em quantidade e velocidade jamais imaginadas. Pela lógica da sociedade consumista, se mais e mais pessoas estão tendo melhores condiçóes financeiras, era de esperar que o número de pessoas felizes crescesse com o mesmo vigor. Especialmente no mundo ocidental, a correlação entre crescimento econômico e felicidade é uma das "verdades" mas difundidas e propagadas pelos economistas e líderes políticos mais respeitados.

Discorrer sobre a ética empresarial aplicada ao consumo traduz-se numa aprofundada reflexão sobre as condutas corporativas num sistema de mercado. É muito mais que simplesmente divisar a problemática ética do consumidor, enquanto subárea da ética do 
marketing. Em verdade, o desafio aqui proposto, enfoca o fenômeno do consumo como algo que atinge indiscriminadamente a todos os seres viventes, especialmente aos humanos. Este é um desafio que nutre a visão da vida cotidiana atrelada a ciência da economia, mas que antes de tudo, privilegia a ciência da ética, com sua carga de motivaçóes, identidades, juízos, crenças e ideias morais.

\section{Conclusões}

A sociedade de consumo tem como motor propulsor do ato de consumir as facilidades de acesso ao crédito e promove a satisfação antecipada de desejos que caracterizam um modo hedonista, onde a busca pelo prazer imediato parece não ter limites. Sáo malefícios deste modelo produtivo a indução do fenômeno social nocivo do hiperconsumo e o fenômeno jurídico do superendividamento que afastam a sociedade das práticas éticas que promovem o consumo sustentável.

A sociedade de consumo náo conseguiu proteger o homem contemporâneo dos sentimentos de ansiedade, das frustraçóes e do medo, mas a nova ordem cultural na contemporaneidade valoriza os laços emocionais e sentimentais, a subjetividade e as relaçóes afetivas mais duradouras.

O consumo e o ato de consumir são inescapáveis a condição da existência digna e a necessidade de se perpetuar enquanto ser vivente. Mas a tipologia das diversas formas de consumo pode adoecer os humanos, levando-os a centralizar a satisfaçáo dos seus desejos nas aquisiçốes que lhe são ofertadas e promovidas pelo mercado de consumo.

O acúmulo desnecessário de produtos e serviços estimula o consumismo. A hipérbole dos atos consumistas configura o quadro doentio ao qual se denomina hiperconsumismo.

Os fornecedores são cada vez mais compelidos a implantar novas técnicas mercadológicas que cumpra o poder de atrair e fidelizar consumidor. Isto exigirá o estudo e o discernimento por parte dos estrategistas empresariais do que o marketing chama de modismos, tendências e megatendências.

A ética e a economia, enquanto ciências, tem o mesmo objeto, estudam o homem. A primeira estuda as açóes humanas em relação à sua moralidade, e a segunda estuda a sociedade e a satisfação das necessidades por meios da escassez de recursos quantitativamente limitados.

Os consumidores do futuro estarão cada vez mais preocupados com a sustentabilidade. Privilegiará não apenas o preço, mas também a especificidade dos produtos diante da diversidade e do correspondente poder de segmentação do mercado de consumo. 


\section{Referências}

BARBOSA, Lívia. CAMPBELL, Colin. Cultura, Consumo e Identidade. Rio de Janeiro: Editora FGV, 2006.

BAUMAN, Zygmunt. Sociedade do consumo e do crédito náo funciona mais. Programa Milênio, Globo News. Entrevista sobre concedida em 27 de janeiro de 2012. Disponível em: <http://www.conjur.com.br/2012-jan-27/ideias-milenio-zygmunt-bauman-sociologo-polones>. Acesso em 24 de Mai.15.

CAMPBELL, Colin. Eu compro, logo sei que existo: as bases metafísicas do consumo moderno. In Barbosa, Lívia \& Campbell, Colin (org). Cultura, Consumo e Identidade Rio de Janeiro: Editora FGV, 2006.

COMIN, Fabio Scorsolini. Resenha: A felicidade paradoxal: ensaios sobre a sociedade de hiperconsumo de Gilles Lipovetsky. Disponível em: <http://www.scielo.br/ scielo.php?script=sci_arttext\&pid=S1413-73722009000100024>. Acesso em 24 de Mai.15.

DIEHL, Bianca Tams (Org.). Educação para o consumo. Curitiba: Multideia, 2014.

DRUCKER, Peter. O melhor de Peter Drucker: obra completa. São Paulo: Nobel, 2002.

EFING, Antônio Carlos. Contratos e Procedimentos Bancários à Luz do Código de Defesa do Consumidor. 2. ed. São Paulo: Editora Revista dos Tribunais, 2012.

Fundamentos do direito nas Relaçóes de Consumo. 3. ed. Curitiba: Juruá, 2011.

FERREIRA, Aurélio Buarque de Holanda. Novo Dicionário Aurélio da Língua Portuguesa. $3^{\text {a }}$.ed. São Paulo, Positivo, 2004.

GONÇALVES, Marco Antônio. CESCON, Everaldo. Ética e consumo: o consumo como estratégia ético-política. Conjectura: Filos. Educ. Caxias do Sul, v. 18, n. 3, set./dez. 2013. Disponível em: <http://www.ucs.br/etc/revistas/index.php/conjectura/article/download/2187/1420>. Acesso em 22 de Mai.15.

GIANNETTI, Eduardo. Felicidade. São Paulo: Companhia das Letras, 2003.

KOTLER, Philip. Administração de Marketing: análise, planejamento, implementação e controle. 5 ed. São Paulo: Atlas, 1998.

; KELLER, K. L. Administração de Marketing. 12. ed. São Paulo: Pearson Prentice Hall, 2006.

LIPOVETSKY, Gilles. A felicidade paradoxal: ensaio sobre a sociedade de hiperconsumo. Tradução de Maria Lucia Machado. São Paulo: Companhia das Letras, 2007, 
MARTINS, Ernesto. Educação, consumo e participaçáo comunitária. Gestin, ano III, n. 3, p. 27-35, dez. 2004. Disponível em: <http://repositorio.ipcb.pt/handle/10400.11/1256>. Acesso em: 17 mai. 2015.

NUNES, Gilcerlândia Pinheiro Almeida. Resenha: A Felicidade Paradoxal: ensaio sobre a sociedade de hiperconsumo. Revista Inter-Legere, no 5 - Reflexóes. Disponível em: <http://www.cchla.ufrn.br/interlegere/05/pdf/le01.pdf>. Acesso em 23 Abr. 15.

POPCORN, F. O Relatório Popcorn: Centenas de Ideias de Novos Produtos, Empreendimentos e Novos Mercados. Rio de Janeiro: Elsevier, 1993.

RIBEIRO, Marcia Carla Pereira; ALVES, Giovani Ribeiro Rodrigues. Desenvolvimento E Reforma Institucional: Os Exemplos do BNDES e das Sociedades Estatais no Brasil. In: SILVEIRA, Vladimir Oliveira da; SANCHES, Samyra Naspolini; COUTO, Monica Bonetti (Org.). Direito e Desenvolvimento no Brasil do Século XXI. IPEA: Brasília, 2013, v. 1, p. 151-176.

RUSCHEINSKY, Aloisio (Org.). Educação Ambiental. Abordagens múltiplas. 2. ed. Porto Alegre: Penso, 2012.

SCHWERINER, Mário Ernesto René. Comportamento do Consumidor: identificando necejos e supérfluos essenciais. Saraiva: São Paulo, 2006.

SEN, Amartya. Sobre Ética e Economia. São Paulo: Cia das Letras, 2006.

SILVA, Ana Beatriz Barbosa. Mentes Consumistas: do consumismo à compulsão por compras. 1. ed. São Paulo: Globo (Principium), 2014.

SMITH, Adam. A Riqueza das Naçóes. 1976. Tradução Roberto Franco Valente. Editora Zahar: Rio de Janeiro, 2008.

TACHIZAWA, Takeshy. Gestáo socioambiental: Estratégias na nova era de sustentabilidade. Rio de Janeiro: Elsevier, 2008.

TIROLE, Jean. Economista Jean Tirole, da França, ganha o Nobel de Economia de 2014. Do G1, em Sáo Paulo. 13/10/2014 08h05. Disponível em: <http://g1.globo.com/economia/noticia/2014/10/jean-tirole-ganha-o-nobel-de-economia.html>. Acesso em: 25 Mai.15.

VENTURA, Rodrigo. Mudanças no Perfil do Consumo no Brasil: Principais Tendências nos Próximos 20 Anos. Relatório Macoplan, 2010. Disponível em: <http: www.macroplan.com.br/documentos/artigomacroplan2010817182941.pdf>. Acesso em 16 de Mai.15.

WEBER, Max. A Ética Protestante e o Espírito do Capitalismo. Tradução José Carlos Mariani de Macedo. São Paulo: Companhia das Letras, 2004. 